
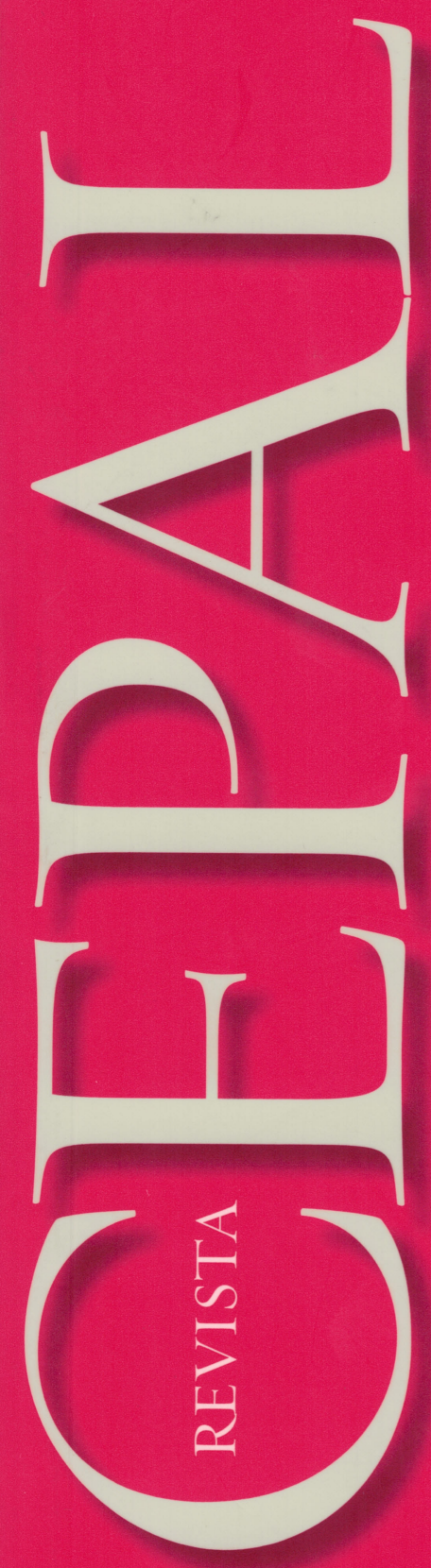

COMISIÓN

ECONÓMICA PARA AMÉRICA LATINA

Y EL CARIBE

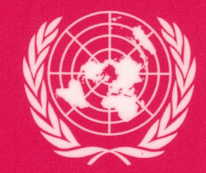

NACIONES UNIDAS
La formación de capital en América Latina: Un siglo y medio de dinámica macroeconómica

XAVIER TAFUNELL

Crecimiento económico y medio ambiente ADOLFO FIGUEROA

MERCOSUR: Tendencias de internacionalización y capacidades tecnológicas

ISABEL ÁlVAREZ, BRUNo B. Fischer y José Miguel NATERA

Estructura productiva y distribución funcional del ingreso:

Una aplicación del modelo de insumo-producto

PEDRo QUARESMA DE ARAUJO

Gran Buenos Aires: Polarización de ingresos, clase media e informalidad laboral, 1974-2010

FERNANDO GROISMAN

Desigualdad y logro académico en Chile

PABLO MuÑoZ H. Y AMAIA REDONDO S.

Heterogeneidad estructural y sus determinantes en la manufactura mexicana, 1994-2008

RAÚl VÁZqueZ LóPEZ

México: Valor agregado en las exportaciones manufactureras GERARDO FUJII G. Y ROSARIO CERVANTES M.

La economía política de las transferencias fiscales a los gobiernos regionales del Perú

LEONARDO E. LETELIER S. Y GONZALO NEYRA A.

Chile: ¿Es eficaz la patente por no uso de derechos de aguas? Christian VAlenZuela, ROdRigo Fuster y AlejandRo León 


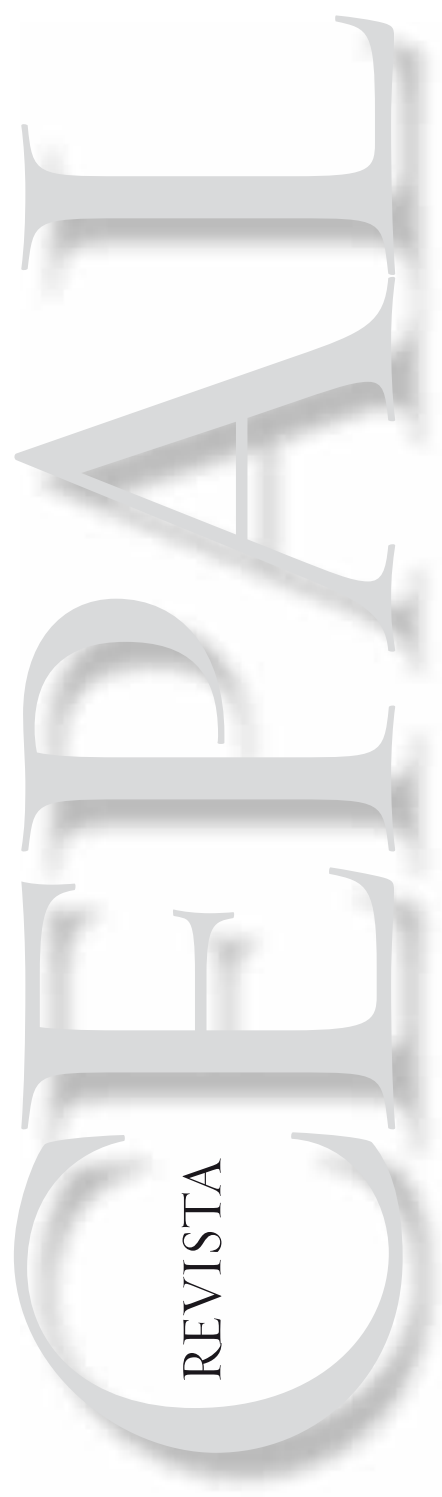

COMISIÓN

ECONÓMICA PARA

AMÉRICA LATINA

Y EL CARIBE

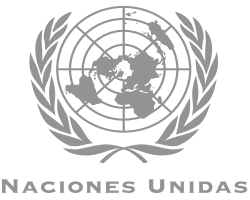

C [ D? 


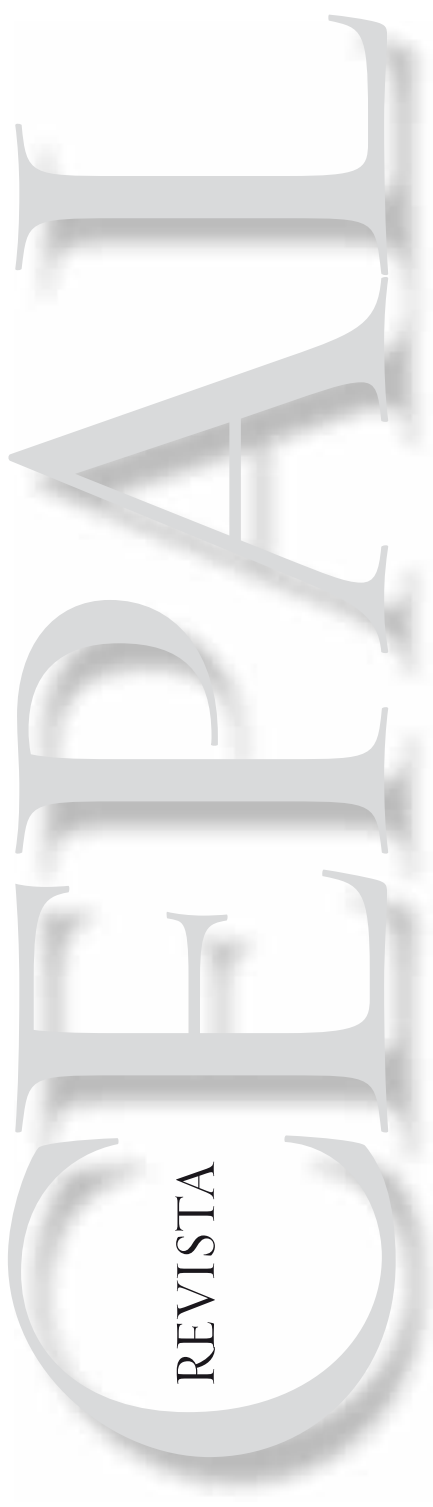

COMISIÓN

ECONÓMICA PARA AMÉRICA LATINA

Y EL CARIBE
ALICIA BÁRCENA

Secretaria Ejecutiva

ANTONIO PRADO

Secretario Ejecutivo Adjunto
OSVALDO SUNKEL

Presidente del Consejo Editorial

ANDRÉ HOFMAN

Director

Miguel TORRES

Editor Técnico

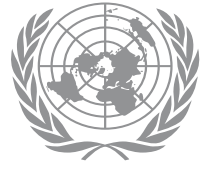

NACIONES UNIDAS 
La Revista CEPAL — así como su versión en inglés, CEPAL Review - se fundó en 1976 y es una publicación cuatrimestral de la Comisión Económica para América Latina y el Caribe, de las Naciones Unidas, con sede en Santiago de Chile. Goza, ello no obstante, de completa independencia editorial y sigue los procedimientos y criterios académicos habituales, incluyendo la revisión de sus artículos por jueces externos independientes. El objetivo de la Revista es contribuir al examen de los problemas del desarrollo socioeconómico de la región, con enfoques analíticos y de políticas, en artículos de expertos en economía y otras ciencias sociales, tanto de Naciones Unidas como de fuera de ella. La Revista se distribuye a universidades, institutos de investigación y otras organizaciones internacionales, así como a suscriptores individuales.

Las opiniones expresadas en los artículos firmados son las de los autores y no reflejan necesariamente los puntos de vista de la organización. Las denominaciones empleadas y la forma en que aparecen presentados los datos no implican, de parte de la Secretaría, juicio alguno sobre la condición jurídica de países, territorios, ciudades o zonas, o de sus autoridades, ni respecto de la delimitación de sus fronteras o límites.

La suscripción anual (tres números) a la Revista CEPAL en español cuesta 30 dólares y la suscripción por dos años, 50 dólares. Los precios de la Revista en inglés son de 35 y 60 dólares, respectivamente. El precio del ejemplar suelto en español o inglés es de 15 dólares, incluidos los gastos de envío.

El texto completo de la Revista puede también obtenerse en la página web de la CEPAL (www.cepal.org), en forma gratuita.

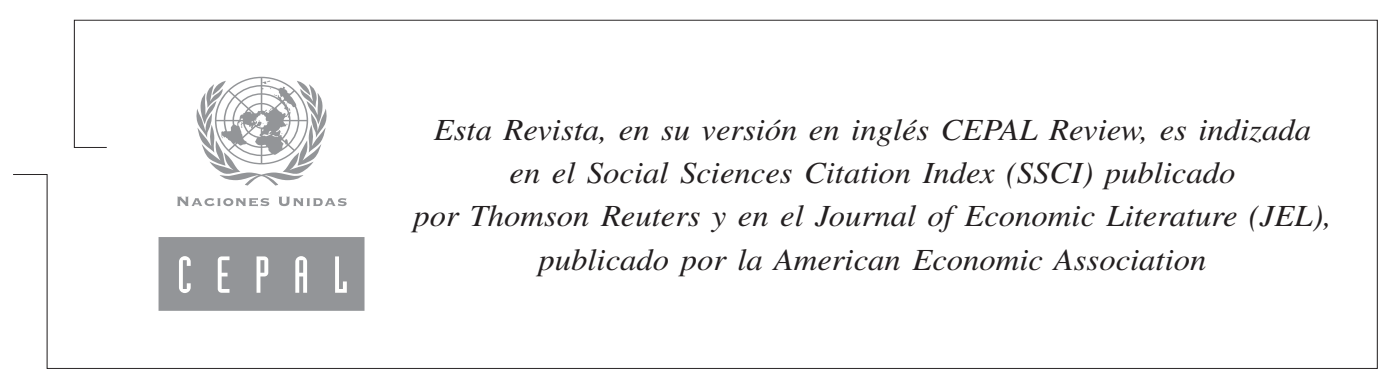

Para suscribirse, envíe su solicitud a Publicaciones de la CEPAL, Casilla 179-D, Santiago de Chile, o al fax (562) 210-2069 o a publications@eclac.cl. El formulario de suscripción puede solicitarse por correo postal o electrónico o descargarse de la página web de la Revista: http://www.cepal.org/revista/noticias/paginas/5/20365/suscripcion.pdf.

Publicación de las Naciones Unidas

ISSN 0252-0257

ISBN 978-92-1-221101-5

LC/G.2556-P

Copyright (C) Naciones Unidas, abril de 2013. Todos los derechos están reservados

Impreso en Santiago de Chile

La autorización para reproducir total o parcialmente esta obra debe solicitarse al Secretario de la Junta de Publicaciones. Los Estados miembros y sus instituciones gubernamentales pueden reproducir esta obra sin autorización previa. Solo se les solicita que mencionen la fuente e informen a las Naciones Unidas de tal reproducción. En todos los casos, las Naciones Unidas seguirán siendo el titular de los derechos de autor y así deberá hacerse constar en las reproducciones mediante la expresión "ㄷ Naciones Unidas 2013", o el año correspondiente. 


\section{Í N D I C E}

La formación de capital en América Latina: Un siglo y medio de dinámica macroeconómica

Xavier Tafunell

Crecimiento económico y medio ambiente

Adolfo Figueroa

MERcosur: Tendencias de internacionalización y capacidades tecnológicas

Isabel Álvarez, Bruno B. Fischer y José Miguel Natera

Estructura productiva y distribución funcional del ingreso:

Una aplicación del modelo de insumo-producto

Pedro Quaresma de Araujo

Gran Buenos Aires: Polarización de ingresos, clase media e informalidad laboral, 1974-2010

Fernando Groisman

Desigualdad y logro académico en Chile

Pablo Muñoz. H. y Amaia Redondo S.

Heterogeneidad estructural y sus determinantes en la manufactura mexicana, 1994-2008

Raúl Vázquez López.

México: Valor agregado en las exportaciones manufactureras

Gerardo Fujii G. y Rosario Cervantes M.

La economía política de las transferencias fiscales a los gobiernos regionales del Perú

Leonardo E. Letelier S. y Gonzalo Neyra A.

Chile: ¿Es eficaz la patente por no uso de derechos de aguas?

Christian Valenzuela, Rodrigo Fuster y Alejandro León

Orientaciones para los colaboradores de la Revista CEPAL 
Notas explicativas

En los cuadros de la presente publicación se han empleado los siguientes signos:

... Tres puntos indican que los datos faltan o no están disponibles por separado.

- La raya indica que la cantidad es nula o despreciable.

Un espacio en blanco en un cuadro indica que el concepto de que se trata no es aplicable.

- Un signo menos indica déficit o disminución, salvo que se especifique otra cosa.

, La coma se usa para separar los decimales.

/ La raya inclinada indica un año agrícola o fiscal, p. ej., 2006/2007.

- El guión puesto entre cifras que expresan años, p. ej., 2006-2007, indica que se trata de todo el período considerado, ambos años inclusive.

Salvo indicación contraria, la palabra "toneladas" se refiere a toneladas métricas, y la palabra "dólares", a dólares de los Estados Unidos. Las tasas anuales de crecimiento o variación corresponden a tasas anuales compuestas. Debido a que a veces se redondean las cifras, los datos parciales y los porcentajes presentados en los cuadros no siempre suman el total correspondiente. 


\title{
Heterogeneidad estructural y sus determinantes en la manufactura mexicana, 1994-2008
}

\author{
Raúl Vázquez López
}

RESUMEN

En este artículo se analizan el estancamiento de la productividad y la creciente heterogeneidad estructural en la manufactura mexicana en el período 1994-2008. La estimación de indicadores de dispersión tradicionales para 200 clases, 50 ramas y 9 divisiones corrobora la ampliación observada en otros trabajos de las brechas en términos de eficiencia productiva entre actividades globalizadas e industrias tradicionales, documentando a un nivel más desagregado tanto la profundización de esta tendencia en la primera década de este siglo como las características particulares de la heterogeneidad intrasectorial. Otros resultados obtenidos mediante la aplicación de una técnica de tipo diferencial estructural, son el nulo aporte del cambio estructural al incremento de la productividad y la concentración del progreso tecnológico en un pequeño número de actividades con muy diversos patrones de inserción en la economía doméstica pero caracterizadas por reducidos grados de integración local y bajo contenido de valor agregado en los bienes que fabrican.

PALABRAS CLAVE

CLASIFICACIÓN JEL

AUTOR
Industria, producción industrial, productos manufacturados, medición, evaluación, productividad, estadísticas industriales, México

L60, O14, O40

Raúl Vázquez López es investigador titular “B” del Instituto de Investigaciones Económicas de la Universidad Nacional Autónoma de México (UnAM), Unidad de Economía Industrial.ravazz@hotmail.com 


\section{I}

\section{Introducción}

La utilización de una metodología histórico-estructural basada en el estudio de los cambios en el tiempo de las relaciones entre los diferentes segmentos de una nación, tanto a nivel económico como político y social, condujo a los pensadores pioneros de la Comisión Económica para América Latina y el Caribe (CEPAL) a subrayar la importancia de las formas de integración de los distintos estratos del aparato productivo y del avance de un proceso de homogeneización de este para el desarrollo de los países latinoamericanos. En particular, Furtado (1961) y Pinto (1965 y 1970) señalaron que la modernización de estructuras en desarrollo y dependientes no solo reduce, sino que mantiene e incluso puede acrecentar las diferencias de productividad entre las diversas actividades.

Esta reflexión pudiera explicar que en los países más avanzados de América Latina - como es el caso de México, tras la adopción del llamado modelo "neoliberal" implementado principalmente por medio de la desregulación económica, la privatización de industrias estatales estratégicas y la liberalización comercial— la reestructuración manufacturera redundara en la estratificación y polarización de la estructura productiva y, en consecuencia, en un ensanchamiento de las brechas entre distintos sectores industriales en términos de eficiencia (Mortimore y Peres, 2001). De hecho, a nivel microeconómico, las crecientes asimetrías en materia de modernización entre un número reducido de empresas insertas en cadenas de valor global (CGV por sus siglas en inglés) capitaneadas por empresas transnacionales (ETN) y un amplio grupo de pequeñas y medianas empresas cada vez más rezagadas han tenido por colofón que el incremento en el diferencial entre los niveles de productividad de las distintas clases de actividad se extienda incluso al ámbito de las relaciones intrasectoriales (Kupfer y Rocha, 2005).

En este contexto, en el presente artículo se plantean varios objetivos de forma simultánea. En primer lugar, dar continuidad y revitalizar la perspectiva y el debate estructural asumidos por la teoría latinoamericana del desarrollo. En un segundo momento, analizar para el período 1994-2008 la evolución de la heterogeneidad estructural tal y como fue definida por esta corriente de pensamiento en el caso de la manufactura mexicana, sector considerado clave en la estrategia de apertura al exterior implementada a partir de mediados de los años ochenta en el país. Finalmente, sobre la base de metodologías recientemente utilizadas por la CEPAL, realizar los ejercicios estadísticos necesarios al mayor nivel de desagregación posible para profundizar en la evaluación de los efectos del cambio estructural en los niveles de productividad y los tipos de heterogeneidad presentes en el sector.

En consecuencia, luego de esta Introducción, el trabajo se organiza de la siguiente manera: en la segunda sección se aborda el tema de la heterogeneidad estructural y la relevancia de la articulación productiva de acuerdo con el enfoque estructuralista de la CEPAL; en la tercera sección se revisan los estudios recientes en que se utilizan metodologías similares para analizar la evolución de la productividad en América Latina y particularmente en el caso de la industria en México. En la sección IV se presentan los resultados de las estimaciones de los niveles de productividad y de los indicadores básicos de la heterogeneidad estructural para distintos niveles de agregación de la manufactura mexicana. En la sección V, tras analizar los determinantes de la evolución de la productividad y evaluar los efectos del cambio estructural en la eficiencia de las clases de actividad, ramas y divisiones del sector mediante una descomposición de Fabricant, se profundiza sobre algunas características y formas de organización y funcionamiento de las industrias "líderes" del patrón de especialización mexicano. Por último, en la sección VI se entregan las principales conclusiones. 


\section{II}

\section{La heterogeneidad estructural en el pensamiento latinoamericano}

A partir de los años cincuenta, en el marco de análisis teórico elaborado por la CEPAL se señalan dos características centrales que definen la condición "periférica" de las economías latinoamericanas: i) la especialización en algunos escasos sectores especialmente primarios e industriales de menor intensidad tecnológica y baja elasticidad de ingreso de la demanda, y ii) la existencia de grandes diferencias en la productividad del trabajo en relación con los países centrales, así como entre las distintas "capas técnicas" que conforman su estructura productiva (Rodríguez, 1980). Para Aníbal Pinto (1965, 1970 y 1971), precursor del concepto de la heterogeneidad, la estrategia de industrialización mediante sustitución de importaciones en la región permitió la creación de un sector moderno no exportador, con niveles de productividad superiores al promedio del sistema e incluso similares a los del complejo exportador, de tal forma que fruto de la diversificación "hacia dentro", el estereotipo de aparato productivo "dual" - propio de los países latinoamericanos en sus primeras fases de desarrollo- se transforma en uno heterogéneo estructural. Cabe señalar que este rasgo se profundiza en el caso de las economías en desarrollo de grado superior (Furtado, 1962) en las fases de fabricación de bienes intermedios y de consumo duradero pesado, basadas en tecnologías modernas y de mayor densidad de capital.

Considerando la experiencia histórica de los países desarrollados, Pinto propone entonces transferir recursos en dirección de los estratos modernos, así como difundir el progreso técnico al resto del aparato productivo mediante el "efecto de arrastre" de los sectores líderes, definidos como aquellos con mayores niveles de productividad. De igual forma, Furtado (1963), siguiendo la tradición de los modelos de cambio estructural con oferta ilimitada de mano de obra, como los de Lewis (1955), Jorgenson (1961) y Fei y Ranis (1961), señala la necesidad de trasladar trabajadores de los sectores atrasados a los modernos como un primer paso para dinamizar la demanda. En su argumentación incluye los principios del análisis keynesiano, pues el incremento de productividad resultante del cambio en la composición del empleo provoca aumentos salariales que diversifican el consumo y a su vez transforman la estructura productiva en un sentido de mayor eficiencia.

En síntesis, un aparato productivo con niveles muy dispares de productividad sectorial, poco integrado y dotado de una capacidad insuficiente para transmitir y diversificar el progreso técnico, se inserta internacionalmente en términos desfavorables mediante la exportación de productos de bajo valor agregado. De este modo, de dicho funcionamiento deriva un tejido institucional poco propenso a la acumulación de capital y la generación de tecnología, lo que se traduce en un excedente de mano de obra y salarios en su gran mayoría próximos a los de subsistencia, estratificando así de forma asimétrica al tipo de consumo y a la sociedad en su conjunto (Bielschowsky, 2009).

Siguiendo estas premisas, el tema de la heterogeneidad ha sido recientemente retomado por la CEPAL desde una visión que pone el acento en la importancia de los efectos del cambio tecnológico en las estructuras productivas. En este enfoque, los cuellos de botella estructurales se reproducen fundamentalmente debido al ensanchamiento de la brecha tecnológica en relación con los países avanzados (Holland y Porcile, 2005), y el origen de la heterogeneidad en el tejido productivo se estudia "a partir del comportamiento estratégico de los agentes económicos, la identificación de las barreras y de los determinantes que afectan a la creación y difusión de capacidades tecnológicas" (Cimoli, 2005, pág. 6). En el análisis se subraya entonces la relevancia de la capacidad de cada sistema productivo para traducir el conocimiento codificado en competencias empleadas en las empresas, y se extiende también el estudio de las relaciones entre segmentos productivos a un complejo entramado de vínculos sistémicos entre las empresas, las organizaciones y el marco institucional (Cimoli y Dosi, 1995).

Aunque en esta perspectiva se privilegia el análisis de variables propias del estudio del cambio tecnológico, se mantiene una idea central en las reflexiones clásicas de la teoría del desarrollo según la cual la industria es el sector con mayores efectos de arrastre en la economía e incluye actividades que por su naturaleza son capaces de asimilar, reproducir y generar el progreso técnico 
(Prebisch, 1962; Singer, 1950). Desde esta perspectiva general, la creciente dualidad productiva entre actividades manufactureras modernas — vinculadas a las dinámicas globales - y otras atrasadas —ligadas sobre todo a un mercado interno en contracción y en que gravitan cada vez más las importaciones- es consecuencia de una apertura comercial acelerada que cuestiona la esencia misma del modelo implementado a partir de los años ochenta en México. De forma más específica, en esta visión se señala la evolución de la estructura manufacturera mexicana hacia formas más homogéneas como clave para el desarrollo productivo nacional y, en términos generales, para una distribución del ingreso más equitativa.

\section{III}

\section{Estudios de la evolución de la productividad en México y América Latina}

Con el fin de capturar y diferenciar el peso tanto del traslado del factor trabajo entre sectores productivos como del cambio tecnológico en la determinación de la evolución de la productividad en la región, autores ligados a la CEPAL han desarrollado distintos acercamientos al tema de la heterogeneidad utilizando técnicas genéricas que parten de la metodología diferencial estructural (shiftshare $)^{1}$. En relación con un período de tiempo prolongado (1960-2003), la CEPAL (2007) encuentra, con respecto a una muestra de nueve economías, que el crecimiento del valor agregado por puesto de trabajo alcanzó un promedio anual de un $1 \%$. Los resultados indican, sin embargo, una gran diferencia entre los indicadores de los distintos países y se destaca la importancia del efecto de recomposición de la fuerza laboral en la variación total del producto por empleado (efecto estructural): $70 \%$ del cambio promedio en la productividad del trabajo en la región. De hecho, en cuatro de las nueve naciones (Bolivia (Estado Plurinacional de), México, Perú y Venezuela (República Bolivariana de) la productividad intrínseca — relativa al progreso tecnológico ${ }^{2}$ — se redujo, "lo que refleja un alejamiento respecto de la frontera productiva” (CEPAL, 2007, pág. 32).

\footnotetext{
${ }^{1}$ Este procedimiento permite descomponer el crecimiento total de la productividad del trabajo en un cierto período entre crecimiento de la productividad dentro de las ramas, transferencia de mano de obra hacia ramas más productivas (efecto de transferencia estática), y transferencia del trabajo hacia las ramas más dinámicas, es decir, ramas que muestran tasas de crecimiento de la productividad más elevadas (efecto de transferencia dinámico).

${ }^{2}$ La CEPAL define el efecto estructural como el aporte de la recomposición sectorial de la fuerza de trabajo al nivel de productividad; y el efecto intrínseco, como la variación de la productividad del trabajo atribuible a los cambios en la productividad intrínseca de los sectores, es decir, a las variaciones imputables al progreso tecnológico (CEPAL, 2007).
}

Por el contrario, en la industria manufacturera, en el estudio de la CEPAL se aprecia que la productividad tuvo un incremento del $22 \%$ en el lapso considerado debido a que la productividad intrínseca registró un crecimiento del $33 \%$. Al respecto, en el trabajo de Holland y Porcile (2005) se confirma que los aumentos de este componente son el principal determinante de los avances en el indicador de la industria en todos los países de la muestra (Argentina, Brasil, Chile, Colombia, México y Uruguay). Con excepción de México, en los años noventa estas naciones registran tasas de crecimiento de la productividad industrial significativamente mayores que las alcanzadas en los decenios pasados, lo que obedece al incremento del 63,9\% de la productividad intrínseca, que compensa con creces la declinación en el aporte de los efectos de tipo estructural fuertemente determinada por los procesos de privatización, desregulación económica y liberalización comercial en la región.

Con respecto al período 1970-2002, los resultados también confirman un aumento del empleo en las actividades industriales de menor productividad y el escaso aporte del cambio estructural a la eficiencia productiva, lo que motiva una creciente heterogeneidad en los complejos fabriles de la región. En el caso concreto de México, a partir de la adopción del modelo "neoliberal" en los años ochenta, la productividad laboral en el conjunto de la economía ha tendido al estancamiento. Así se demuestra en el estudio de Romero (2009) en relación con los efectos de la apertura comercial, donde se estima en $0,5 \%$ anual la tasa de crecimiento promedio de la productividad del trabajo en toda la economía durante el período 1982-2003, cifra muy inferior a la registrada en las cuatro décadas anteriores caracterizadas por altos incrementos en el cociente del PIB por trabajador. Los cálculos presentados por la CEPAL (2007) confirman 
esta observación: la tasa de crecimiento anual de la productividad en México pasa de 3,7\% en los años sesenta a $1,3 \%,-1,8 \%$ y $0,3 \%$, respectivamente, en los siguientes decenios.

En lo que concierne a los determinantes de estas tasas para el caso mexicano, en el trabajo de Romero se señala la tendencia descendente del efecto estructural entre 1961 y 2003, lo que supone que el proceso de desarrollo en el país no se ha traducido en una reubicación del factor trabajo en favor de actividades pujantes en el largo plazo. A su vez, en el documento de la CEPAL, aunque el efecto estructural es positivo en el conjunto de este período y permite compensar una reducción de la productividad intrínseca vinculada a la ausencia de cambio tecnológico, su tendencia es negativa en términos generales. No obstante, en ambos estudios se destaca claramente un deterioro de la contribución del componente estructural a la evolución de la productividad a partir de los años ochenta. En Romero (2009), el efecto estructural se relaciona con un incremento anual de la productividad inferior a un 1\% en el período 1984-2003, llegando incluso a registrar un aporte negativo en los años comprendidos entre 1992 y 1995. En el documento de la CEPAL, por su parte, se constata que mientras en los períodos 1960-1972 y 1973-1981 el efecto estructural contribuyó al aumento de la productividad con 166 dólares y 215 dólares del año 2000 de valor agregado por trabajador en promedio anual, respectivamente, en el período 1982-2003 el aporte se limitó a 77 dólares en los mismos términos constantes.

A nivel de la industria, los resultados son aún más desalentadores; Holland y Porcile (2005) estiman una contribución negativa del efecto de interacción ligado a la reasignación de trabajadores a sectores donde la productividad está creciendo en cada uno de los decenios del período 1970-2000 y particularmente en los años noventa $(-1,26 \%,-3,31 \%$ y $-8,44 \%$, respectivamente). Mientras tanto, la CEPAL (2007) documenta un aporte de 11 dólares del año 2000 al incremento de la productividad laboral de la manufactura mexicana en todo el lapso 1960-2003 por parte del efecto estructural en su conjunto, cifra en línea con la realidad de la mayoría de los países latinoamericanos, dado que el dato es igualmente de 11 dólares en el Brasil y Costa Rica y de 12 en la República Bolivariana de Venezuela en los mismo términos, por solo dar algunos ejemplos. Finalmente, Capdevielle confirma: "Desde los años setenta, el componente que determinó el aumento de la productividad manufacturera fue el incremento de esta dentro de cada rama, mientras que el cambio en la composición de la producción por reasignación e interacción fue poco relevante" (Capdevielle, 2005, pág. 115).

En cuanto a la evolución del componente intrínseco, las cifras son un poco menos claras debido a las discrepancias en las metodologías utilizadas y, en especial, a los distintos niveles de agregación tomados en cuenta en los ejercicios. Según la CEPAL, a diferencia del caso general latinoamericano, el aumento de la productividad generado por el cambio tecnológico en la manufactura mexicana es también reducido a lo largo de todo del período 1960-2003, e incluso inferior al aporte del efecto estructural (9 dólares del años 2000). Empero, en las estimaciones de Holland y Porcile, el incremento de la productividad intrínseca en la manufactura $(23,78 \%$ en promedio para el lapso 1970-2000) si bien es menor que el promedio de los países en la muestra, es superior al efecto de reasignación de trabajadores. Por último, Capdevielle (2005) explica el crecimiento del indicador por dicho concepto en los años 1988-2003 (67,07 pesos de 1993) debido a un aumento de la eficiencia en las actividades no maquiladoras que, sin embargo, no se basa en mejoras de tipo técnico: “... pudo haber tenido su origen en procesos de racionalización de personal en un contexto en que la apertura comercial intensificaba la disputa por los mercados locales" (Capdevielle, 2005, pág. 115).

En síntesis y pese a las diferencias estadísticas constatadas, los pocos estudios estructurales existentes de la evolución de la productividad en la industria mexicana muestran un pobre desempeño del indicador en el sector, así como el escaso aporte (por debajo del promedio latinoamericano) tanto del cambio estructural como del progreso tecnológico a la eficiencia del aparato manufacturero desde el fin de la estrategia de industrialización mediante sustitución de importaciones y, en particular, durante el período del modelo "neoliberal". En este sentido, las tendencias observadas se relacionan con la estrategia de inserción productiva internacional del país, consistente en especializarse en ciertas ramas y en segmentos específicos de la producción en el interior de industrias "líderes" determinadas, por medio de la explotación de mano de obra poco calificada. Estrategia compatible de hecho con los intereses de los grandes grupos transnacionales que deslocalizan segmentos del proceso productivo en procura de abaratar sus costos (sobre todo laborales) y de esta forma hacer más eficiente y consolidar sus redes globales de fabricación (Gereffi, 1995). 


\section{IV}

\section{Evolución de la heterogeneidad estructural por clases de actividad en la manufactura mexicana en el período 1994-2008}

En el marco de la polarización de la estructura de la manufactura mexicana y de la profundización y pretendida extensión del fenómeno de la heterogeneidad al ámbito intrasectorial, un estudio con cierto grado de precisión de la evolución de los diferenciales de productividad en el sector exige un tratamiento estadístico al nivel más desagregado posible (inexistente a la fecha debido a la falta de series de información oficiales largas y consistentes). Con el fin de solventar este requerimiento y analizar la heterogeneidad intrasectorial destacada por ciertos autores, se construyó una base de datos en que se estiman, a precios constantes de diciembre de 2003, los valores de la productividad laboral de forma mensual y para cada uno de los años del período 1994-2008 con respecto a 200 clases de actividad de la manufactura mexicana a partir de la Encuesta Industrial Mensual (EIM) en la Clasificación Mexicana de Actividades Económicas y Productos (CMAP) del Instituto Nacional de Estadística y Geografía (INEGI) ${ }^{3}$. Además, procurando afinar el análisis, se distinguieron dos subperíodos de igual duración (1994-2001 y 2001-2008) a objeto de facilitar las comparaciones y tomando en cuenta la capacidad que comúnmente se le ha reconocido a la estrategia de liberalización económica de haber generado empleo en sus primeros años de aplicación en el país.

En términos generales, los resultados indican que durante los períodos 1994-2001 y 2001-2008 los niveles de productividad en el sector manufacturero mexicano se han incrementado de forma moderada a ritmos anuales de un $2,3 \%$ y un $2,6 \%$, respectivamente (véase el cuadro 1 ). La tendencia al estancamiento de dichos niveles en un

\footnotetext{
${ }^{3}$ Tras sumar los valores mensuales, los datos anuales son deflactados a precios de 2003 utilizando el Índice Nacional de Precios Productor del sector manufacturero presentado por el Banco de México (BANXICO). La estimación del indicador resulta entonces del cociente entre la producción bruta total y las horas-hombre trabajadas para los diferentes grupos de actividad. El indicador de productividad no puede ser calculado para 5 clases de actividad $(321111,382301,383202,384204,385006)$ de las 205 de la encuesta, porque no existe información sobre el valor de producción ni acerca de las horas-hombre trabajadas en ellas en el período 2003-2008.
}

marco de constante cambio tecnológico hace patente la ausencia tanto de la generación de externalidades positivas en el entramado de fabricación nacional como de una infraestructura productiva e institucional adecuada que amplíe los rendimientos específicos de cada actividad.

En el caso de México, las diferencias en la evolución del indicador, tanto entre las distintas divisiones, ramas y clases de actividad como entre los dos períodos considerados, son además marcadas. Mientras que en el primer lapso (1994-2001) las ramas referentes a la industria farmacéutica, automotriz y fábricas de cemento, cal y yeso, esta última ligada a la actividad constructora, tuvieron incrementos de productividad que superan el $5,5 \%$ anual, las divisiones más tradicionales como la textil y la de la madera registraron en su conjunto incluso disminuciones en su relación producción-trabajo (véase el cuadro 1). Por su parte, el período 2001-2008 se caracteriza por un estancamiento generalizado de los niveles de productividad en la manufactura en un contexto de episodios recurrentes de contracción de los mercados internacionales, dato alarmante si se toma en cuenta que históricamente la productividad ha dejado de elevarse en muy contados períodos.

Asimismo, entre 2001 y 2008 se destacan altas tasas anuales de crecimiento del indicador, superiores al $10 \%$ en las dos ramas de las industrias metálicas básicas, así como un incremento del $8,2 \%$ en la fabricación de sustancias químicas básicas (véase el cuadro 1). Sin embargo, es necesario precisar en primer término que las variaciones observadas en los niveles de productividad pueden verse sesgadas por la desigual evolución de los precios en las distintas actividades de la manufactura. En consecuencia, algunas industrias pueden presentar aumentos en su productividad que no se relacionan ni con la adopción de procesos, maquinaria innovadora o ambos, ni con una mayor inversión en recursos. Al respecto, las elevadas tasas de crecimiento de la relación producción-trabajo en las ramas referentes a las industrias metálicas básicas a partir del año 2001 obedecen en gran medida a los ingentes incrementos en el valor de los bienes fabricados. De hecho, el Índice Nacional 
CUADRO 1

Evolución de la productividad laboral de las divisiones

y ramas seleccionadas del sector manufacturero, 1994-2008

(En pesos de diciembre de 2003 por hora-hombre trabajada y porcentajes)

\begin{tabular}{|c|c|c|c|c|c|}
\hline \multirow{2}{*}{ División/rama } & \multicolumn{3}{|c|}{$\begin{array}{c}\text { Producción por } \\
\text { hora-hombre trabajada }\end{array}$} & \multicolumn{2}{|c|}{$\begin{array}{l}\text { Tasa anual de } \\
\text { crecimiento }\end{array}$} \\
\hline & 1994 & 2001 & 2008 & 1994-2001 & 2001-2008 \\
\hline I Productos alimenticios, bebidas y tabaco & 465,9 & 489,2 & 535,8 & 0,7 & 1,3 \\
\hline Rama 3112 Elaboración de productos lácteos & 656,9 & 726,7 & 689,6 & 1,5 & $-0,7$ \\
\hline Rama 3130 Industria de las bebidas & 396,1 & 457,4 & 565,8 & 2,1 & 3,1 \\
\hline II Textiles, prendas de vestir e industria del cuero & 197,0 & 168,8 & 187,2 & $-2,2$ & 1,5 \\
\hline III Industria de la madera y productos de madera & 187,9 & 173,3 & 176,7 & $-1,1$ & 0,3 \\
\hline IV Papel, productos de papel, imprentas y editoriales & 360,8 & 372,7 & 365,8 & 0,5 & $-0,3$ \\
\hline V Sustancias químicas, derivados del petróleo, productos de caucho y plástico & 496,0 & 577,4 & 686,4 & 2,2 & 2,5 \\
\hline Rama 3512 Fabricación de sustancias químicas básicas & 831,1 & 909,9 & 1584,3 & 1,3 & 8,2 \\
\hline Rama 3521 Industria farmacéutica farmacoquímica & 568,0 & 826,0 & 760,4 & 5,5 & $-1,2$ \\
\hline Rama 3522 Fabricación de otras sustancias y productos químicos & 606,5 & 707,3 & 741,2 & 2,2 & 0,7 \\
\hline VI Productos de minerales no metálicos, excepto derivados del petróleo y carbón & 406,2 & 455,5 & 479,5 & 1,6 & 0,7 \\
\hline $\begin{array}{l}\text { Rama } 3691 \text { Fabricación de cemento, cal, yeso y otros productos sobre la base de } \\
\text { minerales no metálicos }\end{array}$ & 538,4 & 812,5 & 785,5 & 6,1 & $-0,5$ \\
\hline VII Industrias metálicas básicas & 836,9 & 934,4 & 1942,7 & 1,6 & 11,0 \\
\hline Rama 3710 Industria básica del hierro y del acero & 844,2 & 1043,6 & 2149,0 & 3,1 & 10,9 \\
\hline Rama 3720 Industrias básicas de metales no ferrosos & 822,8 & 746,0 & 1559,6 & $-1,4$ & 11,1 \\
\hline VIII Productos metálicos, maquinaria y equipo & 519,4 & 711,4 & 755,3 & 4,6 & 0,9 \\
\hline Rama 3841 Industria automotriz & 895,0 & 1314,3 & 1377,6 & 5,6 & 0,7 \\
\hline IX Otras industrias manufactureras & 189,3 & 174,7 & 189,6 & $-1,1$ & 1,2 \\
\hline Total de la manufactura & 446,1 & 523,4 & 625,0 & 2,3 & 2,6 \\
\hline
\end{tabular}

Fuente: elaboración propia sobre la base de datos de Instituto Nacional de Estadística y Geografía (INEGI), "Encuesta industrial mensual (CMAP), 205 clases de actividad económica", 2011 [en línea] http://dgcnesyp.inegi.org.mx/cgi-win/bdieintsi.exe/NIVZ101290009000020002\#ARBOL

de Precios Productor (INPP) de la división VII, correspondiente a industrias metálicas básicas, señala un alza del 202,7\% en el período 2002-2008, en circunstancias que el índice general para el conjunto de la manufactura en esos años se acrecentó en un 56,3\% ${ }^{4}$.

Aunque como lo específica Romero (2009), los valores absolutos de la proporción producción-trabajo varían en función de la relación capital-trabajo propia de cada actividad, la distancia entre las industrias tradicionales y las de mayor inserción en el ámbito global se ha ampliado a raíz de la apertura comercial. A manera de ejemplo, mientras que en 1994 la productividad de la industria automotriz representaba 4,5 y 4,8 veces la registrada por las divisiones textil y de la madera, respectivamente, en 2008 estos coeficientes eran de 7,4 y 7,8 veces ${ }^{5}$. Cabe señalar que en este caso el efecto de los precios puede ser considerado como residual, dado que en los tres grupos el crecimiento del INPP es inferior al del sector en su conjunto. De enero de 1994 a diciembre

\footnotetext{
4 Calculado a partir de Banco de México (BANXICO, 2011).

5 Calculado a partir de los datos del cuadro 1 .
}

de 2008, el valor de los bienes de la rama ensambladora de automóviles y camiones creció $235,4 \%$, el de los productos textiles $197,5 \%$ y el de los de la madera $204,1 \%$, siendo la cifra para la manufactura de $261,9 \%{ }^{6}$.

Al respecto, en los indicadores estadísticos tradicionales de dispersión se observa el grado creciente de heterogeneidad estructural en el sector manufacturero mexicano, tanto de forma horizontal - entre los elementos de los diferentes niveles de agregación- como vertical - en el interior de los grupos de actividad, sean divisiones o ramas (heterogeneidad intrasectorial) - . Como se puede apreciar en el cuadro 2, tanto el valor de la desviación estándar como el del coeficiente de variación se incrementan a mayor nivel de desagregación, lo que confirma la relevancia de un análisis de la heterogeneidad horizontal por clases de actividad. De igual forma, la evolución de ambos indicadores para las diferentes muestras señala a grandes rasgos que tras dos períodos cortos, uno de alza (1994-1996) y otro posterior de declinación (1997-1999), a partir del año 2000 se

6 Véase BANXICO (2011). 
produce una clara y sostenida tendencia a la ampliación de las brechas en términos de productividad a todo lo ancho del sector, como se muestra en el gráfico 1 en el caso de la desviación estándar.

Corresponde subrayar en particular el aumento del coeficiente de variación y de la desviación estándar de la productividad a nivel de las divisiones del año 2001 al 2008 (59\% y 108,4\%, respectivamente). De hecho, mientras que en 2008 tres de las nueve divisiones tienen niveles de producción por horahombre trabajada inferiores a los 190 pesos de 2003, las industrias metálicas básicas registran 1.942,7 pesos (véase el cuadro 1). Al nivel más desagregado posible, el análisis para las 200 clases de actividad indica que la desviación estándar creció $67,2 \%$ en el período 1994-2008, destacándose un aumento de $45,6 \%$ entre 2001 y 2008 (véase el cuadro 2). En este último subperíodo (2001-2008), el proceso de expansión de la heterogeneidad se produce a la par del estancamiento generalizado de la productividad, lo que expresa el progresivo aislamiento de las actividades competitivas ligadas al funcionamiento global.

CUADRO 2

Indicadores de dispersión de la productividad laboral por niveles de agregación del sector manufacturero, 1994-2008

(En pesos de diciembre de 2003 por hora-hombre trabajada y porcentajes)

\begin{tabular}{|c|c|c|c|c|c|c|c|c|c|c|}
\hline \multirow{2}{*}{$\begin{array}{l}\text { Años/período } \\
\text { Dispersión/agregación }\end{array}$} & \multicolumn{2}{|c|}{1994} & \multicolumn{2}{|c|}{2001} & \multicolumn{2}{|c|}{2008} & \multicolumn{2}{|c|}{$\begin{array}{c}\text { Tasa de } \\
\text { crecimiento } \\
1994-2008\end{array}$} & \multicolumn{2}{|c|}{$\begin{array}{c}\text { Tasa de } \\
\text { crecimiento } \\
\text { 2001-2008 }\end{array}$} \\
\hline & $\mathrm{CV}$ & $\mathrm{DE}$ & $\mathrm{CV}$ & $\mathrm{DE}$ & $\mathrm{CV}$ & $\mathrm{DE}$ & $\mathrm{CV}$ & $\mathrm{DE}$ & $\mathrm{CV}$ & $\mathrm{DE}$ \\
\hline Divisiones & 51,5 & 209,3 & 58,6 & 264,2 & 93,2 & 550,6 & 90,0 & 163,1 & 59,0 & 108,4 \\
\hline Ramas & 69,1 & 304,1 & 79,1 & 373,6 & 89,7 & 520,1 & 29,8 & 71,0 & 13,4 & 39,2 \\
\hline Clases de actividad & 85,5 & 371,8 & 93,9 & 427,1 & 112,9 & 621,7 & 32,0 & 67,2 & 20,2 & 45,6 \\
\hline
\end{tabular}

Fuente: elaboración propia sobre la base de datos de Instituto Nacional de Estadística y Geografía (INEGI), "Encuesta industrial mensual (CMAP), 205 clases de actividad económica", 2011 [en línea] http://dgcnesyp.inegi.org.mx/cgi-win/bdieintsi.exe/NIVZ101290009000020002\#ARBOL

CV: coeficiente de variación.

DE: desviación estándar.

GRÁFICO 1

\section{Desviación estándar de la productividad para diferentes niveles de agregación, 1994-2008 \\ (En pesos de diciembre de 2003 por hora-hombre trabajada)}

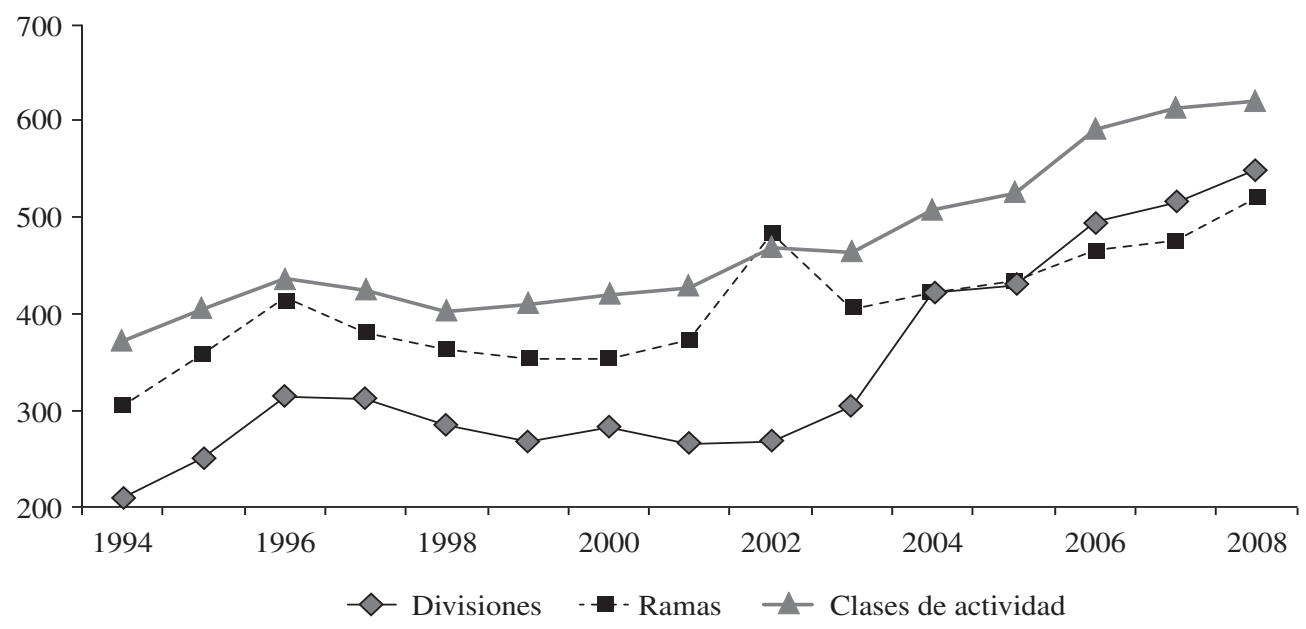

Fuente: elaboración propia sobre la base de datos de Instituto Nacional de Estadística y Geografía (INEGI), "Encuesta industrial mensual (CMAP), 205 clases de actividad económica", 2011 [en línea] http://dgcnesyp.inegi.org.mx/cgi-win/bdieintsi.exe/NIVZ101290009000020002\#ARBOL 
En este sentido, los resultados obtenidos son consistentes con los hallazgos de Holland y Porcile (2005), quienes encuentran que en los años noventa existió en México un proceso de sigma-divergencia entre los sectores industriales. En sus estimaciones, el coeficiente de variación calculado a partir de la productividad de solo 28 sectores se incrementó en 35,6\% de 1990 a 1999 y el coeficiente de Gini de dicha muestra pasó de 0,25 a 0,29 en el mismo período. El ejercicio aquí realizado permite asimismo complementar y extender el análisis de estos autores en cuanto a que en la primera década del milenio la respuesta de la productividad del trabajo continuó siendo débil y la tendencia al aumento de la dispersión no se revirtió, sino que por el contrario parece haberse agravado como resultado de un patrón de crecimiento que Holland y Porcile calificaran como de baja capacidad de absorción del subempleo y del desempleo.

En lo que atañe a la heterogeneidad intrasectorial, al estimar los indicadores tomando en cuenta los niveles de productividad de las clases de actividad dentro de cada división, resulta que el proceso de ampliación de las brechas fue más lento con respecto al que se produjo entre los sectores en el período 1994-2008, así lo sugiere el que las tasas de crecimiento de los indicadores de dispersión sean por lo general más bajas. Resaltan igualmente las marcadas diferencias en la evolución tanto de la desviación estándar como del coeficiente de variación entre los sectores considerados, mientras que en la división "Papel, productos del papel, imprentas y editoriales" estas variaciones fueron incluso negativas $(-6,8 \% \mathrm{y}-0,5 \%$, respectivamente) en la división "Industrias metálicas básicas" la desviación estándar se incrementó en 296,9\% (véase el cuadro 3).

Si bien el número de clases de actividad que componen cada división pudiera sesgar estos resultados haciendo inestables los indicadores, sobre todo en los sectores con un pequeño número de actividades, como es el caso de la división "Industrias metálicas básicas", lo cierto es que la evidencia para el período 1994-2008 parece indicar que existen agrupaciones manufactureras en las que la heterogeneidad intrasectorial creció moderadamente o incluso se redujo (productos alimenticios, bebidas y tabaco; textiles, prendas de vestir e industria del cuero; papel, productos de papel, imprentas y editoriales), y otras en que el incremento fue considerable (industria de la madera y productos de madera; sustancias químicas, derivados del petróleo, productos de caucho y plástico; productos de minerales no metálicos, excepto derivados del petróleo y carbón; industrias metálicas básicas; y productos metálicos, maquinaria y equipo).

CUADRO 3

\begin{abstract}
Indicadores de dispersión de la productividad laboral a nivel de clases de actividad por división de la manufactura, 1994-2008

(En pesos de diciembre de 2003 por hora-hombre trabajada y porcentajes)
\end{abstract}

\begin{tabular}{|c|c|c|c|c|c|c|c|c|}
\hline \multirow{2}{*}{$\begin{array}{l}\text { Años/período } \\
\text { Dispersión/división }\end{array}$} & \multicolumn{2}{|c|}{1994} & \multicolumn{2}{|c|}{2001} & \multicolumn{2}{|c|}{2008} & \multicolumn{2}{|c|}{$\begin{array}{c}\text { Tasa de } \\
\text { crecimiento } \\
\text { 1994-2008 }\end{array}$} \\
\hline & $\mathrm{CV}$ & $\mathrm{DE}$ & $\mathrm{CV}$ & $\mathrm{DE}$ & $\mathrm{CV}$ & $\mathrm{DE}$ & $\mathrm{CV}$ & $\mathrm{DE}$ \\
\hline Productos alimenticios, bebidas y tabaco (38 clases) & 72,8 & 514,3 & 70,1 & 499,6 & 80,2 & 615,2 & 10,2 & 19,6 \\
\hline Textiles, prendas de vestir e industria del cuero ( 31 clases $)$ & 61,0 & 128,4 & 76,4 & 138,8 & 72,0 & 133,8 & 18,0 & 4,2 \\
\hline Industria de la madera y productos de madera ( 5 clases) & 31,6 & 59,8 & 38,6 & 71,4 & 54,3 & 104,7 & 72,2 & 75,1 \\
\hline Papel, productos de papel, imprentas y editoriales ( 9 clases) & 42,2 & 154,4 & 39,9 & 147,9 & 42,0 & 143,9 & $-0,5$ & $-6,8$ \\
\hline $\begin{array}{l}\text { Sustancias químicas, derivados del petróleo, productos de } \\
\text { caucho y plástico ( } 38 \text { clases) }\end{array}$ & 65,2 & 343,6 & 63,3 & 364,3 & 85,5 & 636,6 & 31,0 & 85,3 \\
\hline $\begin{array}{l}\text { Productos de minerales no metálicos, excepto derivados del } \\
\text { petróleo y carbón ( } 16 \text { clases) }\end{array}$ & 88,4 & 279,8 & 126,4 & 460,3 & & 437,2 & 30,9 & 56,3 \\
\hline Industrias metálicas básicas ( 7 clases) & 53,2 & 378,6 & 60,8 & 503,5 & 83,4 & 1502,8 & 56,7 & 296,9 \\
\hline Productos metálicos, maquinaria y equipo (53 clases) & 80,6 & 286,3 & 110,6 & 419,6 & 97,1 & 435,8 & 20,5 & 52,2 \\
\hline Otras industrias manufactureras ( 3 clases) & 27,8 & 44,8 & 38,3 & 54,5 & 40,5 & 60,5 & 45,7 & 35,1 \\
\hline Total de la manufactura & 85,5 & 371,8 & 93,9 & 427,1 & 112,9 & 621,7 & 32,0 & 67,2 \\
\hline
\end{tabular}

Fuente: elaboración propia sobre la base de datos de Instituto Nacional de Estadística y Geografía (INEGI), "Encuesta industrial mensual (CMAP), 205 clases de actividad económica”, 2011 [en línea] http://dgcnesyp.inegi.org.mx/cgi-win/bdieintsi.exe/NIVZ101290009000020002\#ARBOL.

CV: coeficiente de variación.

DE: desviación estándar. 
Las diferencias en los ritmos de crecimiento de los dos tipos de heterogeneidad antes definidos pueden explicarse al interpretar el fenómeno a nivel intrasectorial como resultado de la profundización de la dinámica desarticuladora del aparato productivo local, que se origina en el tipo de inclusión de la manufactura mexicana en el ámbito global. Desde esta perspectiva, la creciente dualidad productiva se manifiesta a nivel general entre sectores a consecuencia de un proceso de especialización excluyente, que se explica por el cambio de modelo económico y, a nivel más específico, en el interior de cada uno de los sectores a causa de la posterior extensión del proceso de la maquila bajo formas más complejas.

\section{Manufactura mexicana: análisis de los determinantes de la productividad} y de la heterogeneidad estructural

En esta sección, a partir de la metodología empleada por estudios previos sobre el tema discutidos en el comienzo de este artículo, se utilizan los indicadores de productividad construidos para las 200 clases de actividad de la manufactura mexicana para el período 1994-2008, con el fin de evaluar la contribución del progreso tecnológico y del cambio estructural a la evolución observada tanto de la productividad como de la heterogeneidad estructural en el sector. Mediante una técnica estadística de tipo diferencial estructural (Maddison, 1952; CEPAL, 2007), se descomponen las variaciones en los niveles de productividad en dos efectos antes definidos (intrínseco y estructural) para distintos niveles de agregación (a nivel de división, rama y clase de actividad) y períodos de análisis.

En la descomposición genérica conocida como fórmula de Fabricant se pondera la importancia de cada concepto (progreso tecnológico y cambio estructural) por los coeficientes $S_{i}{ }^{t}$ y $\mathrm{P}_{i}{ }^{0}$, como se muestra a continuación:

$$
\begin{aligned}
& \left(P^{T}-P^{0}\right)=\left[\left(P_{1}^{T}-P_{1}^{o}\right) \cdot S_{1}^{T}+\left(P_{2}^{T}-P_{2}^{o}\right) \cdot S_{2}^{T}\right]+ \\
& {\left[\left(S_{1}^{T}-S_{1}^{o}\right) \cdot P_{1}^{o}+\left(S_{2}^{T}-S_{2}^{o}\right) \cdot P_{2}^{o}\right]}
\end{aligned}
$$

Luego de cambiar la base temporal de la ponderación y generalizar la fórmula para $n$ sectores, la CEPAL (2007) obtiene la siguiente descomposición del diferencial entre dos niveles agregados de productividad en dos momentos en el tiempo:

$$
\begin{aligned}
& \left(P^{T}-P^{0}\right)=\sum_{i=1}^{n}\left[\left(P_{i}^{T}-P_{i}^{0}\right),\left(S_{i}^{0}-S_{i}^{T}\right) / 2\right]+ \\
& \sum_{i=1}^{n}\left[\left(S_{i}^{T}-S_{l}^{0}\right) \cdot\left(P_{i}^{0}-P_{i}^{T}\right) / 2\right]
\end{aligned}
$$

donde $\mathrm{P}_{\mathrm{i}}^{\mathrm{t}}$ es la productividad en el sector $\mathrm{i}(\mathrm{i}=1,2, \ldots \mathrm{n})$ en el instante $\mathrm{t}=0, \mathrm{~T}$ y $\mathrm{S}_{\mathrm{i}}{ }^{\mathrm{t}}$ es la participación del sector i $(i=1,2, \ldots \mathrm{n})$ en la población activa total empleada en $\mathrm{t}=0, \mathrm{~T}$. El primer término del lado derecho de la ecuación representa la variación de la productividad del trabajo atribuible a los cambios en la productividad intrínseca de $\operatorname{los} n$ sectores. El segundo término indica el aporte de la recomposición sectorial de la fuerza de trabajo. Si el empleo crece más en los sectores de alta productividad intrínseca, el efecto neto será positivo; si, por el contrario, son los sectores de baja productividad los receptores netos, el resultado final de la recomposición factorial será negativo (CEPAL, 2007, pág. 28).

En la reformulación que se presenta a continuación, la estimación se realiza para los años 1994 y 2008, en el caso de las 200 clases de actividad de la manufactura, por lo que la participación de cada clase de actividad tanto en el empleo como en la evolución de la productividad se refiere al total del sector manufacturero. A manera de ejemplo,

$$
\begin{aligned}
& \left(P^{08}-P^{94}\right)=\sum_{i=1}^{n}\left[\left(P_{i}^{08}-P_{i}^{94}\right) \cdot\left(S_{i}^{94}+S_{i}^{08}\right) / 2\right]+ \\
& \sum_{i=1}^{n}\left[\left(S_{i}^{08}-S_{l}^{94}\right) \cdot\left(P_{i}^{94}+P_{i}^{08}\right) / 2\right]
\end{aligned}
$$


Dado que en esta descomposición las ponderaciones dependen del promedio de dos años de referencia aleatorios, sucede que los resultados varían en función del grado de desagregación con que se trabaja, es decir, que si bien en todos los casos, la sumatoria de los efectos intrínseco y estructural da un mismo efecto total de cambio en la productividad entre los dos años considerados, por el contrario, la sumatoria de cada uno de los conceptos no arroja los mismos resultados si se toman en cuenta las 200 clases de actividad, las 50 ramas o las 9 divisiones. A pesar de que las diferencias obtenidas no son considerables ni modifican en absoluto las conclusiones del análisis, con el fin de evitar discrepancias estadísticas, los resultados del ejercicio que se presentan para cada rama y división se obtienen mediante la sumatoria de los valores de las clases que agrupan.

En lo referente a los hallazgos y tal como se muestra en el cuadro 4, se establece primeramente lo mencionado en líneas anteriores: el aumento en la productividad para el conjunto de la manufactura en el período estudiado (178,94 pesos de 2003, es decir, 2,4\% en promedio anual) y sobre todo en su primer lapso que abarca de 1994 a 2001 ( 77,27 pesos y 2,3\% en los mismos términos) debe considerarse reducido si se toma en cuenta que la tasa de crecimiento anual de dicho indicador fue de un 2,7\% entre 1970 y 1990 (CEPAL, 2007, pág. 62). En un segundo momento, resalta que no existe prácticamente ningún aporte del cambio estructural al incremento en el indicador; en efecto, el desplazamiento de trabajadores de clases de actividad de baja productividad a otras de mayor eficiencia solo explica un 6,2\% del aumento en la producción por hora-hombre trabajada registrado a todo lo largo del período 1994-2008. Una hipótesis plausible, cuyo alcance es ajeno al presente trabajo, es que a pesar de las transformaciones en la industria manufacturera, no existió cambio estructural en el sector. Por oposición, el efecto intrínseco, es decir, los incrementos de productividad dentro de cada clase de actividad por reorganización productiva o progreso técnico, explican el 93,8\% del crecimiento en la producción por horahombre trabajada en la manufactura ente 1994 y 2008 , y el 95,2\% de su expansión entre 2001 y 2008.

Las estimaciones obtenidas señalan también, independientemente de los niveles de agregación del análisis, altos y crecientes grados de concentración de las prácticas eficientes en la estructura de fabricación. A nivel de gran división, mientras tres de ellas registran una contribución negativa a la evolución de la productividad del sector y otras dos tienen un aporte prácticamente nulo, las cuatro divisiones restantes representan el 102,7\% del efecto total en el indicador y el $99 \%$ del intrínseco en el lapso 1994-2008. De igual forma, a nivel de ramas, tan solo dos de las 50 existentes (industria automotriz e industria básica del hierro y el acero) son responsables en forma conjunta del $52 \%$ del incremento en la productividad de la manufactura mexicana y del $47,9 \%$ del efecto intrínseco total del sector en dicho período (véase el cuadro 5).

Es de especial relevancia que las ramas de mayor contribución al incremento de la producción por horahombre trabajada en la manufactura sean a su vez las de mayores niveles de fabricación en la estructura. De hecho, las ocho ramas con los valores de producción más elevados del sector en 2008 se encuentran a su vez entre los primeros nueve lugares en términos de su aporte al crecimiento de la productividad laboral entre 1994 y 2008. En suma, las mejoras de eficiencia se dan exclusivamente en los polos de especialización del patrón productivo, y se trata por lo general de grandes empresas insertas en dinámicas globales y capaces de realizar economías de escala, lo que confirma una escasa presencia tanto de difusión del progreso técnico en la estructura como de efectos positivos de derrame de las industrias líderes en dirección del resto del sector.

Al respecto, en diversos estudios se documentan a nivel sectorial estos limitados derrames tecnológicos en la manufactura mexicana; Arroyo y Cárcamo (2010) señalan la introducción de innovaciones y capacitación, pero también la permanencia de una amplia mayoría de pequeñas y medianas empresas (pymes) con baja tecnología, mano de obra poco calificada y mínimas habilidades de diseño y administración en la industria textil con posterioridad a la apertura comercial. Por su parte, Castañón, Solleiro y Del Valle (2003) hacen una recopilación de las mejoras tecnológicas en diversas

CUADRO 4

Determinantes de la productividad en el total de la manufactura, 1994-2008

(En pesos de diciembre de 2003

por hora-hombre trabajada)

\begin{tabular}{cccr}
\hline Efectos/período & Intrínseco & Estructural & Total \\
\hline $1994-2001$ & 66,37 & 10,90 & 77,27 \\
$2001-2008$ & 96,75 & 4,92 & 101,67 \\
$1994-2008$ & 167,91 & 11,02 & 178,94 \\
\hline
\end{tabular}

Fuente: elaboración propia sobre la base de datos de Instituto Nacional de Estadística y Geografía (INEGI), "Encuesta industrial mensual (CMAP), 205 clases de actividad económica", 2011 [en línea] http://dgcnesyp. inegi.org.mx/cgi-win/bdieintsi.exe/NIVZ101290009000020002\#ARBOL 
CUADRO 5

Determinantes de la productividad laboral en las divisiones y

ramas seleccionadas del sector manufacturero, 1994-2008

(En pesos de diciembre de 2003 por hora-hombre trabajada)

I Productos alimenticios, bebidas y tabaco

Rama 3112 Elaboración de productos lácteos

Rama 3130 Industria de las bebidas

II Textiles, prendas de vestir e industria del cuero

III Industria de la madera y productos de madera

IV Papel, productos de papel, imprentas y editoriales

V Sustancias químicas, derivados del petróleo, productos de caucho y plástico

Rama 3512 Fabricación de sustancias químicas básicas

Rama 3521 Industria farmacéutica farmoquímica

Rama 3522 Fabricación de otras sustancias y productos químicos

VI Productos de minerales no metálicos, excepto derivados del petróleo y carbón

Rama 3691 Fabricación de cemento, cal, yeso y otros productos sobre la base de

minerales no metálicos

VII Industrias metálicas básicas

Rama 3710 Industria básica del hierro y del acero

Rama 3720 Industrias básicas de metales no ferrosos

VIII Productos metálicos, maquinaria y equipo.

Rama 3841 Industria automotriz

IX Otras industrias manufactureras

Total de la manufactura

\begin{tabular}{rrr}
28,50 & 9,49 & 37,99 \\
2,65 & 5,87 & 8,51 \\
14,78 & $-4,66$ & 10,12 \\
$-3,35$ & $-4,61$ & $-7,96$ \\
$-0,31$ & $-0,86$ & $-1,17$ \\
$-0,42$ & 1,93 & 1,50 \\
30,95 & $-2,70$ & 28,25 \\
14,13 & $-4,94$ & 9,19 \\
5,69 & 6,19 & 11,87 \\
4,62 & 0,93 & 5,55 \\
5,84 & $-2,89$ & 2,95 \\
& & \\
5,71 & $-4,17$ & 1,54 \\
50,02 & 6,66 & 56,68 \\
37,03 & 5,58 & 42,61 \\
12,99 & 1,08 & 14,07 \\
56,74 & 4,17 & 60,91 \\
43,44 & 7,01 & 50,45 \\
$-0,05$ & $-0,16$ & $-0,21$ \\
167,91 & 11,02 & 178,94 \\
\hline
\end{tabular}

Fuente: elaboración propia sobre la base de datos de Instituto Nacional de Estadística y Geografía (INEGI), "Encuesta industrial mensual (CMAP), 205 clases de actividad económica", 2011 [en línea] http://dgcnesyp.inegi.org.mx/cgi-win/bdieintsi.exe/NIVZ101290009000020002\#ARBOL

ramas del sector alimentario, caracterizado por grupos en permanente modernización, subrayando, sin embargo, el papel de estos cambios en calidad de barreras a la entrada de las pymes a la actividad y la consiguiente desintegración de los eslabonamientos de valor locales, como resultado de la falta de difusión de estos avances al ámbito agrícola. Por último, Álvarez (2002) pone en evidencia que las transformaciones en la industria automotriz terminal, una de las más dinámicas de la manufactura mexicana, han dejado poco espacio para la incorporación a la cadena productiva de las empresas domésticas fabricantes de repuestos y propiciado la entrada de nuevas compañías extranjeras al mercado nacional.

Como se desprende del gráfico 2, estas aseveraciones se ven confirmadas al realizar el análisis al nivel más desagregado posible, siendo que tan solo 10 de las 200 clases de actividad consideradas, es decir, un 5\% de la muestra, aportan el $72,3 \%$ de los incrementos en la productividad laboral de la manufactura y el $63,4 \%$ de los aumentos registrados en el indicador por mejoras de eficiencia dentro de cada una de las clases en el lapso 1994-2008. La concentración es incluso mayor en el subperíodo 1994-2001, en el que el efecto total de las 10 clases de mayor contribución al indicador supera al del conjunto de la manufactura, vale decir que al considerar la suma de las 190 clases de actividad restantes, se registra un decremento neto de la productividad laboral y, en consecuencia, un efecto total negativo en esos años. Es de subrayar entonces que el $95 \%$ del sector manufacturero en su conjunto no tuvo avance alguno en materia de productividad durante los siete años posteriores a la entrada en vigor en 1994 del Tratado de Libre Comercio de América del Norte (TLCAN).

Finalmente, diversos aspectos se destacan con respecto a las características de las clases de actividad en que se concentran los incrementos de productividad en el período de estudio 1994-2008 y que son a su vez las actividades con mayor peso en la producción total del sector en $2008^{7}$, es decir, las industrias que podríamos llamar "líderes" del modelo de especialización manufacturero actual. En primera instancia, cabe subrayar los bajos niveles tanto del porcentaje de valor añadido contenido en los productos de estas clases — sobre todo

\footnotetext{
${ }^{7}$ Las siete clases de actividad de mayor nivel de producción en la manufactura en 2008 concentran 36,5\% de la producción total del sector en ese año. Significativamente, son también — con excepción de la clase referente a la fabricación de cerveza- las que registran los mayores incrementos en productividad laboral durante el período 1994-2008.
} 
GRÁFICO 2

Determinantes de la productividad en el total de la manufactura y en diez clases seleccionadas, 1994-2008

(En pesos de diciembre de 2003 por hora-hombre trabajada)

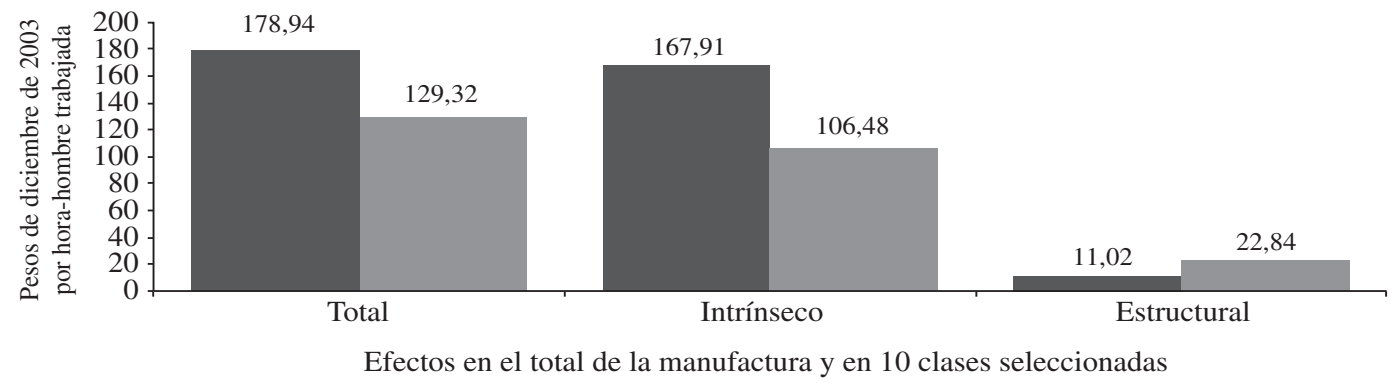

Total manufactura $\square$ Diez clases seleccionadas

Fuente: elaboración propia sobre la base de datos de Instituto Nacional de Estadística y Geografía (INEGI), "Encuesta industrial mensual (CMAP), 205 clases de actividad económica”, 2011 [en línea] http://dgcnesyp.inegi.org.mx/cgi-win/bdieintsi.exe/NIVZ101290009000020002\#ARBOL

si se toma en cuenta el alto grado de modernización de las plantas - como de sus grados de integración con el aparato productivo doméstico.

De hecho, al intentar establecer una tipología de estas actividades líderes, resulta que solo las industrias de las bebidas (fabricación de cerveza y elaboración de refrescos) presentan en 2008 cifras superiores al promedio de la manufactura en sus coeficientes de articulación y de valor agregado en la producción ${ }^{8}$. Además, al representar estas clases en un diagrama cuyos ejes valoran estos coeficientes y tienen por origen los datos del total del sector, se encuentra que dos de las seis consideradas (fabricación y ensamble de automóviles y camiones y fundición, laminación, refinación y extrusión de metales no ferrosos) se ubican en el cuadrante localizado a la izquierda en la parte inferior, es decir, que registran un coeficiente de articulación y una participación del valor añadido en la producción inferiores al promedio de la manufactura (véase el gráfico 3 ).

La representación gráfica sugiere también que no existe un patrón uniforme de funcionamiento en lo referente a las relaciones que mantienen estas actividades con el ámbito doméstico. Mientras la industria de la elaboración de refrescos y otras bebidas no alcohólicas se encuentra altamente integrada a la economía nacional, pues vende el $99,6 \%$ de sus productos al mercado mexicano, mantiene una participación del valor agregado en

\footnotetext{
8 Por su parte, la producción se divide en dos componentes, el consumo intermedio y el valor agregado, datos directamente generados por el INEGI. Aquí se considera la parte del valor agregado en la producción.
}

la producción superior al promedio del sector y presenta el coeficiente de articulación más elevado de las 200 clases de actividad presentes en la base de información. En la situación opuesta se encuentra la fabricación y ensamble de automóviles y camiones, totalmente inserta en eslabonamientos internacionales de valor, la que registra muy bajos niveles en todos estos indicadores, lo que hace referencia entre otros aspectos a una pobre articulación con proveedores locales y a un sesgo de sus ventas en favor del mercado global.

Por último, los datos permiten apreciar el insignificante peso de los montos de inversión en las industrias "dinámicas" de la manufactura mexicana en 2008. A manera de ejemplo, en la fabricación y ensamble de automóviles y camiones se invierte solamente un 5,8\% del valor agregado generado, mientras que en ninguna de las clases de actividad de las industrias metálicas básicas consideradas se alcanza un porcentaje de $2,5 \%$. Sin embargo, conviene destacar que las dos clases (fabricación de productos farmacéuticos y fabricación de cerveza) con los coeficientes de inversión más altos son a su vez las industrias con mayor participación del valor agregado en la producción. Un caso significativo es el de la industria farmacéutica, controlada por grandes corporaciones transnacionales, que registra la participación más alta del valor agregado en la producción entre las clases de actividad líderes del sector. Esta industria fabrica sus productos sobre todo para el mercado interno (el 88,5\% de sus ventas totales), pero utiliza mayormente en sus procesos materias primas e insumos de importación, lo que se traduce en un bajo coeficiente de articulación: $33 \%$ (véase el cuadro 6). 
GRÁFICO 3 Coeficiente de articulacióna y participación del valor agregado en la producción de
actividades líderes del patrón de especialización manufacturerob, 2008
(En porcentajes)

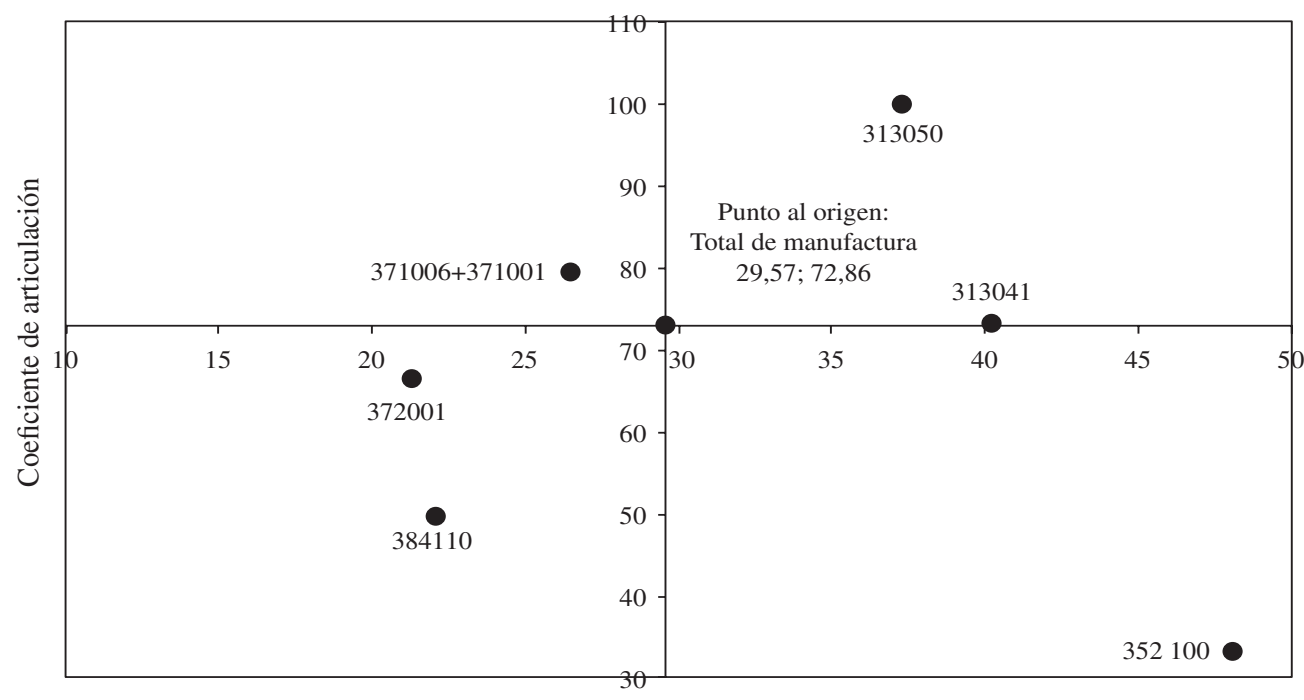

Valor agregado / Producción

Fuente: elaboración propia sobre la base de datos de Instituto Nacional de Estadística y Geografía (INEGI), "Encuesta industrial anual (scian), 231 clases de actividad económica", 2011 [en línea] http://dgcnesyp.inegi.org.mx/cgi-win/bdieintsi.exe/NIVR250130\#ARBOL

a El coeficiente de articulación se calcula como la parte del valor de las materias primas y auxiliares nacionales consumidas en el valor total de las materias primas y auxiliares consumidas en la producción, es decir, se trata de una aproximación a la participación de los insumos locales en el total de insumos consumidos en el proceso productivo.

b Con el fin de dar coherencia al análisis y utilizar los datos obtenidos de las fuentes bajo el Sistema de Clasificación Industrial de América del Norte (SCIAN) en función de las clases de actividad de la Clasificación Mexicana de Actividades Económicas y Productos (CMAP), se realizaron las siguientes equivalencias: $\mathbf{3 8 4 1 1 0}$ (Fabricación y ensamble de automóviles y camiones) corresponde a la rama 3361 del scIAN; $371001+371006$ (Fundición y laminación primaria de hierro y acero y Fabricación de laminados y otros productos de acero) corresponden a la rama 3311; 372001 (Fundición, laminación, refinación y extrusión de metales no ferrosos) corresponde a la clase de actividad 331419; 352100 (Fabricación de productos farmacéuticos) corresponde a la rama 3254; 313050 (Elaboración de refrescos y otras bebidas no alcohólicas) corresponde a la clase de actividad 312111; y 313041 (Fabricación de cerveza) corresponde a la clase de actividad 312120.

CUADRO 6

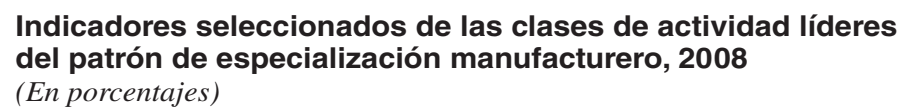

\begin{tabular}{|c|c|c|c|c|}
\hline Clases de actividad & $\begin{array}{l}\text { Valor agregado/ } \\
\text { Producción }\end{array}$ & $\begin{array}{l}\text { Coeficiente de } \\
\text { articulación }\end{array}$ & $\begin{array}{l}\text { Participación de ventas } \\
\text { nacionales en el total }\end{array}$ & $\begin{array}{l}\text { Inversión/Valor } \\
\text { agregado }\end{array}$ \\
\hline Fabricación y ensamble de automóviles y camiones & 22,08 & 49,67 & 18,88 & 5,76 \\
\hline $\begin{array}{l}\text { Fundición y laminación primaria de hierro y acero }+ \\
\text { Fabricación de laminados y otros productos de acero }\end{array}$ & 26,48 & 79,37 & 72,93 & 0,22 \\
\hline $\begin{array}{l}\text { Fundición, laminación, refinación y extrusión de } \\
\text { metales no ferrosos }\end{array}$ & 21,29 & 66,55 & 25,71 & 2,41 \\
\hline Fabricación de productos farmacéuticos & 48,11 & 33,01 & 88,54 & 6,31 \\
\hline Elaboración de refrescos y otras bebidas no alcohólicas & 37,31 & 99,99 & 99,58 & 3,99 \\
\hline Fabricación de cerveza & 40,20 & 73,10 & 67,87 & 15,30 \\
\hline Total de la manufactura & 29,57 & 72,86 & 74,50 & 5,97 \\
\hline
\end{tabular}

Fuente: elaboración propia sobre la base de datos de Instituto Nacional de Estadística y Geografía (INEGI), "Encuesta industrial anual (sCIAN), 231 clases de actividad económica", 2011 [en línea] http://dgcnesyp.inegi.org.mx/cgi-win/bdieintsi.exe/NIVR250130\#ARBOL 
En este orden de ideas, la heterogeneidad estructural en la manufactura mexicana se traduce también en distintos modos de funcionamiento y organización empresarial en las actividades dinámicas del sector, como resultado de la diversa gama de estrategias de expansión a nivel mundial de las cadenas de valor global (CGV) (Gereffi, 1994; Gereffi, Humphrey y Sturgeon, 2005; Kaplinsky, 2000). Esta heterogeneidad de las

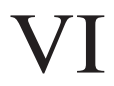

\section{Conclusiones}

En la tradición del pensamiento latinoamericano, los precursores del concepto de la heterogeneidad estructural señalaron que la modernización de estructuras desarticuladas, dependientes tecnológicamente del exterior y desprovistas de la capacidad de transmitir y diversificar el progreso técnico, podía redundar en un crecimiento de los desequilibrios en el seno del aparato productivo. En el caso concreto de la industria manufacturera mexicana, la apertura comercial acelerada y las reformas económicas implementadas a partir de mediados de los años ochenta derivaron en un exiguo proceso de modernización acotado a un número muy reducido de clases de actividad insertas por lo general en CGV. Aun cuando estas actividades "líderes" se rigen en México por una muy diversa gama de estrategias corporativas mundiales que determinan, entre otros muchos aspectos, el tipo y nivel de relaciones que mantienen con el ámbito doméstico, lo cierto es que se caracterizan por reducidos grados de integración local y por fabricar bienes con bajo contenido en valor agregado.

En un marco de segmentación y deslocalización extrema de los procesos de fabricación a nivel global, estas características de las actividades líderes del patrón de especialización manufacturero mexicano se explican por el peso relativo de las importaciones temporales en el precio de los bienes producidos y por la subvaluación que la gobernanza ${ }^{9}$ de las CGV realiza de las actividades efectuadas por sus filiales en el país. Mediante la manipulación de los precios de transferencia a los que

\footnotetext{
9 Kaplinsky define el concepto de gobernanza como el papel de coordinación e identificación de oportunidades dinámicas de realización de rentas, así como de asignación de actividades a los distintos partícipes en el proceso productivo (Kaplinsky, 2000, pág. 124).
}

actividades dinámicas y de su evolución deriva entonces de los intereses particulares de negocio de las empresas transnacionales (ETN) en las diferentes localizaciones, motivaciones que podrían identificarse a grandes rasgos con los determinantes de la inversión extranjera directa (IED), comúnmente detectados por la literatura económica (búsqueda de mercados, de recursos y activos, o de eficiencia) (UNCTAD, 1998; Mallampally y Sauvant, 1999).

se realizan los intercambios intrafirma ${ }^{10}$, la gobernanza suele reflejar los beneficios del conjunto del proceso productivo en localizaciones externas. Como lo señala Katz (2004) para el caso de América Latina, existe una estrecha correlación entre la mayor presencia de subsidiarias de grandes grupos transnacionales en el entramado productivo, sus menores grados de articulación debido a la desintegración vertical de estas empresas en sus operaciones locales, y la caída en los esfuerzos de innovación en los ámbitos nacionales.

En gran parte y a consecuencia del predominio de estos patrones organizativos en las actividades "líderes", se ha producido un estancamiento de los niveles generales de productividad y una ampliación de la heterogeneidad estructural en la manufactura mexicana a raíz de la apertura comercial y sobre todo, según los resultados del ejercicio presentado, en la primera década del presente siglo. Al respecto, los estadísticos tradicionales de dispersión muestran un grado creciente de heterogeneidad en el sector, tanto de forma horizontal como vertical, lo que no solo confirma los resultados obtenidos en los escasos estudios disponibles sobre el tema, sino que permite actualizarlos en lo que respecta a su cobertura temporal y a sus alcances en virtud del mayor nivel de desagregación al que se aplican los ejercicios estadísticos.

En este sentido, uno de los hallazgos relevantes permite distinguir distintos ritmos de crecimiento en los tipos de heterogeneidad destacados, de modo que

\footnotetext{
10 Término técnico comúnmente utilizado en economía para hacer referencia a las operaciones/intercambios realizados entre distintas empresas perteneciente a una misma firma o compañía. En muchas ocasiones, estas empresas se encuentran ubicadas en distintos países y son subsidiarias de una misma casa matriz instalada en un país avanzado.
} 
todo parece indicar que la forma intrasectorial se ha expandido a una velocidad menor. Una hipótesis plausible que pudiera ser corroborada en trabajos posteriores es la interpretación del fenómeno como vinculado al proceso de desarticulación progresiva del aparato de fabricación nacional, consecuencia del carácter altamente especializado de la manufactura mexicana. En el origen de estas tendencias se encuentra la lógica concentradora de la actividad productiva, desarrollada a partir de las condiciones recesivas de la crisis de la deuda externa e inherente al modelo económico establecido a partir de los años ochenta. Mediante la estratificación y la polarización de la estructura del sector, la concentración de la oferta en un reducido número de grandes empresas en casi todos los mercados conllevó la rápida depuración de la planta productiva y estableció las bases del incremento de los diferenciales entre los niveles de productividad de las distintas actividades.

Otro resultado que corrobora con fuerza indicios señalados en trabajos anteriores es el nulo aporte del desplazamiento del factor trabajo, es decir, del cambio estructural, a la evolución de la productividad en la manufactura mexicana en el período 1994-2008. Este elemento es de singular importancia si se toma en cuenta que uno de los principales supuestos teóricos - en torno del cual se argumentó en favor de la estrategia de liberalización comercial y desregulación económica en la década de los ochenta- fue que los empleos destruidos en industrias ineficientes serían compensados con creces por la creación de puestos de trabajo en las "nuevas" actividades dinámicas ligadas a los mercados internacionales. No obstante, la evidencia recabada muestra que a la fecha las empresas insertas en eslabonamientos mundiales no han sido capaces de generar empleos de manera permanente, ni de transmitir capacidades tecnológicas y organizativas al resto del entramado productivo.

En síntesis, el conjunto de elementos anteriormente mencionados sugiere el progresivo aislamiento de las actividades globalizadas en el seno de la estructura y hace evidente la inexistencia de economías de escala dinámicas a nivel sectorial, lo que es propio de una transformación estructural que en la tipología elaborada por Ocampo (2005) se caracterizaría como superficial (shallow) ${ }^{11}$. En este contexto, la continuidad y vigencia de los conceptos centrales del análisis estructuralista latinoamericano apuntarían a una planificación del crecimiento que revirtiera primeramente las tendencias observadas, centrándose en el desarrollo de industrias estratégicas con un elevado potencial de integración local a fin de reconstruir cadenas de producción domésticas.

\footnotetext{
${ }^{11}$ La transformación estructural superficial (shallow) característica consiste en el desarrollo de enclaves exportadores; por lo general, este tipo de transformación se distingue por la debilidad de sus complementariedades (economías de aglomeración y especialización) y de sus procesos de aprendizaje (innovaciones tecnológicas inducidas). Estas dos condicionantes son esenciales para incrementar los niveles de productividad.
}

Álvarez, M. (2002), "Cambios en la industria automotriz frente a la globalización: El sector de autopartes en México", Contaduría y Administración, $\mathrm{N}^{\circ}$ 206, México, D.F., Universidad Nacional Autónoma de México, julio.

Arroyo, M. y M. Cárcamo (2010), "La evolución histórica e importancia económica del sector textil y del vestido en México", Economía y Sociedad, vol. 14, No 25, Michoacán, México, Universidad Michoacana de San Nicolás de Hidalgo, enero-junio.

BANXico (Banco de México) (2011), "Estadísticas en línea. Índice de precios al productor" [en línea] http://www.banxico.org.mx/ SieInternet/consultarDirectorioInternetAction.do?accion $=\mathrm{co}$ nsultarDirectorioCuadros\&sector $=20 \&$ sectorDescripcion $=\%$ CDndices\%20de\%20Precios\%20Productor\%20y\%20de\%20 Comercio\%20Exterior\&locale $=\mathrm{es}$

Bielschowsky, R. (2009), "Sesenta años de la CEPAL: Estructuralismo y neoestructuralismo", Revista de la CEPAL, No 97 (LC/G.2400-P), Santiago de Chile, abril.

Capdevielle, M. (2005), "Globalización, especialización y heterogeneidad estructural en México", Heterogeneidad estructural, asimetrías tecnológicas y crecimiento en América Latina, M. Cimoli (ed.), Santiago de Chile, Comisión Económica para América Latina y el Caribe (CEPAL)/Banco Interamericano de Desarrollo (BID).
Castañón, R., J.L. Solleiro y M. Del Valle (2003), "Estructura y perspectivas de la industria de alimentos en México", Comercio Exterior, vol. 53, № 2, México, D.F, BANCOMEXT, febrero.

CEPAL (Comisión Económica para América Latina y el Caribe) (2007), "Progreso técnico y cambio estructural en América Latina", Documento de trabajo, $\mathrm{N}^{\circ} 136$ (LC/W.136), Santiago de Chile.

Cimoli, M. (comp.) (2005), Heterogeneidad estructural, asimetrías tecnológicas y crecimiento en América Latina, Santiago de Chile, Comisión Económica para América Latina y el Caribe (CEPAL)/Banco Interamericano de Desarrollo (BID).

Cimoli, M. y G. Dosi (1995), "Technological paradigms, patterns of learning and development. An introductory roadmap", Journal of Evolutionary Economics, vol. 5, $\mathrm{N}^{\circ}$ 3, Springer, octubre.

Fei, J. y G. Ranis (1961), Development of the Labour Surplus Economy: Theory and Policy, Homewood, Illinois, R.D. Irwin.

Furtado, C. (1963), "Capital formation and economic development", The Economics of Underdevelopment, A. Agarwala y S. Singh (eds.), Nueva York, Oxford University Press.

(1962), Formación económica del Brasil, México, D.F., Fondo de Cultura Económica.

(1961), Desarrollo y subdesarrollo, México, D.F., Fondo de Cultura Económica. 
Gereffi, G. (1995), "Global production systems and third world development", Global Change, Regional Response: The New International Context of Development, B. Stallings (comp.), Nueva York, Cambridge University Press.

(1994), "The organization of buyer-driven global commodity chains: how U.S. retailers shape overseas production networks", Commodity Chains and Global Capitalism, G. Gereffi y M. Korzeniewicz (eds.), Wesport, Connecticut, Praeger.

Gereffi, G., J. Humphrey y T. Sturgeon (2005), "The governance of global value chains", Review of International Political Economy, vol. 12, $\mathrm{N}^{\circ}$ 1, Taylor \& Francis, febrero.

Holland, M. y G. Porcile (2005), "Brecha tecnológica y crecimiento en América Latina", Heterogeneidad estructural, asimetrías tecnológicas y crecimiento en América Latina, M. Cimoli (ed.), Santiago de Chile, Comisión Económica para América Latina y el Caribe (CEPAL)/Banco Interamericano de Desarrollo (BID).

INEGI (Instituto Nacional de Estadística y Geografía) (2011a), Encuesta Industrial Mensual (EIM) (CMAP), 205 clases de actividad [en línea] http://dgcnesyp.inegi.org.mx/cgi-win/bdieintsi.exe/ NIVZ101290009000020002\#ARBOL

(2011b), Encuesta Industrial Anual (SCIAN), 231 clases de actividad [en línea] http://dgcnesyp.inegi.org.mx/cgi-win/ bdieintsi.exe/NIVR250130\#ARBOL

Jorgenson, D. (1961), "The development of a dual economy", Economic Journal, vol. 71, $\mathrm{N}^{\circ} 282$, Wiley-Blackwell, junio.

Kaplinsky, R. (2000, "Globalization and unequalisation: what can be learned from value chain analysis?", Journal of Development Studies, vol. 37, $\mathrm{N}^{\mathrm{o}}$ 2, Taylor \& Francis, diciembre.

Katz, J. (2004), Industrial Dynamics, Innovation and Development, DRUID Summer Conference, Copenhague.

Kupfer, D. y C. Rocha (2005), "Productividad y heterogeneidad estructural en la industria brasileña", Heterogeneidad estructural, asimetrías tecnológicas y crecimiento en América Latina, M. Cimoli (ed.), Santiago de Chile, Comisión Económica para América Latina y el Caribe (CEPAL)/Banco Interamericano de Desarrollo (BID).

Lewis, A. (1955), The Theory of Economic Growth, Homewood, Illinois, R.D. Irwin.
Maddison, A. (1952), "Productivity in an expanding economy", The Economic Journal, vol. 62, No 245, Wiley-Blackwell, marzo.

Mallampally, P. y K. Sauvant (1999), "La inversión extranjera en los países en desarrollo", Finanzas y Desarrollo, vol. 36, No 1 , Washington, D.C., Fondo Monetario Internacional, marzo.

Mortimore, M. y W. Peres (2001), "La competitividad empresarial en América Latina y el Caribe", Revista de la CEPAL, $\mathrm{N}^{\circ} 74$ (LC/G.2135-P), Santiago de Chile, agosto.

Ocampo, J. (2005), "The quest for dynamic efficiency: structural dynamics and economic growth in developing countries", Beyond Reforms. Structural Dynamics and Macroeconomic Vulnerability, J. Ocampo (coord.), Washington, D.C., Stanford University Press.

Pinto, A. (1971), "El modelo de desarrollo reciente de la América Latina", El Trimestre Económico, vol. 38, № 150, México, D.F., Fondo de Cultura Económica, abril-junio.

(1970), "Naturaleza e implicaciones de la "heterogeneidad estructural" de la América Latina", El trimestre económico, vol. 37, N 145, México, D.F., Fondo de Cultura Económica.

(1965), "Concentración del progreso técnico y de sus frutos en el desarrollo de América Latina", El Trimestre Económico, vol. 32, N 125, México, D.F., Fondo de Cultura Económica.

Prebisch, R. (1962), "El desarrollo económico de la América Latina y algunos de sus principales problemas", Boletín económico de América Latina, vol. 7, $\mathrm{N}^{\circ} 1$, febrero.

Rodríguez, O. (1980), La teoría del subdesarrollo de la CEPAL, México, D.F., Siglo XXI.

Romero, J. (2009), "Medición del impacto de los acuerdos de libre comercio en América Latina: el caso de México", serie Estudios y Perspectivas, $\mathrm{N}^{\circ} 114$ (LC/MEX/L.932), México, D.F., Sede Subregional de la CEPAL en México. Publicación de las Naciones Unidas, $\mathrm{N}^{\circ}$ de venta: S.0X.II.G.107.

Singer, H. (1950), "The distribution of gains between investing and borrowing countries", The American Economic Review, vol. 40, $\mathrm{N}^{\circ}$ 2, Nashville, Tennessee, American Economic Association, junio.

UNCTAD (Conferencia de las Naciones Unidas sobre Comercio y Desarrollo) (1998), World Investment Report. Trends and Determinants (UNCTAD/wIR/1998) Nueva York. Publicación de las Naciones Unidas, $\mathrm{N}^{\circ}$ de venta: E.98.II.D.5. 


$$
\begin{aligned}
& \text { كيفيـة الحصـول على منثـورات الأمـم المتحسدة }
\end{aligned}
$$

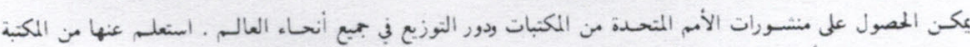

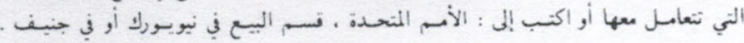

如何购取联合国出版物

联合国出版物在全世界各地的书占和经传处均有发售。请向书后询问或写信到纽约或日内瓦的 联合国销隽组。

\section{HOW TO OBTAIN UNITED NATIONS PUBLICATIONS}

United Nations publications may be obtained from bookstores and distributors throughout the world. Consult your bookstore or write to: United Nations, Sales Section, New York or Geneva.

\section{COMMENT SE PROCURER LES PUBLICATIONS DES NATIONS UNIES}

Les publications des Nations Unies sont en vente dans les librairies et les agences dépositaires du monde entier. Informez-vous auprès de votre libraire ou adressez-vous à : Nations Unies. Section des ventes. New York ou Genève.

КАК ПОЛУЧИТЬ ИЗДАНИЯ ОРГАНИЗАЦИИ ОБЪЕДИНЕННЫХ НАЦИЙ

Издания Организации Объединенных Наций можно купить в книжных магазинах и агентствах во всех районах мира. Наводите справки об изданиях в вашем книжном магазине или пишите по адресу: Организация Объединенных Наций, Секция по продаже изданий, Нью-Йорк или Женева.

\section{COMO CONSEGUIR PUBLICACIONES DE LAS NACIONES UNIDAS}

Las publicaciones de las Naciones Unidas están en venta en librerías y casas distribuidoras en todas partes del mundo. Consulte a su librero o diríjase a: Naciones Unidas. Sección de Ventas. Nueva York o Ginebra.

Las publicaciones de la Comisión Económica para América Latina y el Caribe (CEPAL) y las del Instituto Latinoamericano y del Caribe de Planificación Económica y Social (ILPES) se pueden adquirir a los distribuidores locales o directamente a través de:

Publicaciones de las Naciones Unidas

2 United Nations Plaza, Room DC2-853

Nueva York, NY, 10017

Estados Unidos

Tel. (1 800)253-9646 Fax (1 212)963-3489

E-mail: publications@un.org

\section{Publicaciones de las Naciones Unidas}

Sección de Ventas

Palais des Nations

1211 Ginebra 10

Suiza

Tel. (41 22)917-2613 Fax (41 22)917-0027

Unidad de Distribución

Comisión Económica para América Latina y el Caribe (CEPAL)

Av. Dag Hammarskjöld 3477, Vitacura

7630412 Santiago

Chile

Tel. (56 2)210-2056 Fax (56 2)210-2069

E-mail: publications@cepal.org

Publications of the Economic Commission for Latin America and the Caribbean (ECLAC) and those of the Latin American and the Caribbean Institute for Economic and Social Planning (ILPES) can be ordered from your local distributor or directly through:

United Nations Publications

2 United Nations Plaza, Room DC2-853

New York, NY, 10017

USA

Tel. (1 800)253-9646 Fax (1 212)963-3489

E-mail:publications@un.org

\author{
United Nations Publications \\ Sales Sections \\ Palais des Nations \\ 1211 Geneva 10 \\ Switzerland \\ Tel. (41 22)917-2613 Fax (41 22)917-0027
}

Distribution Unit

Economic Commission for Latin America and the Caribbean (ECLAC)

Av. Dag Hammarskjöld 3477, Vitacura

7630412 Santiago

Chile

Tel. (56 2)210-2056 Fax (56 2)210-2069

E-mail:publications@eclac.org 

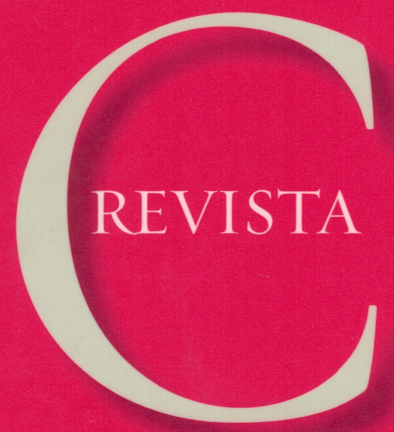

ANDRÉ HOFMAN

Director

MIGUEL TORRES

Editor Técnico

www.cepal.org/revista

\section{CONSEJO EDITORIAL}

\section{OSVALDO SUNKEL}

Presidente

José Antonio Alonso

Oscar Altimir

Renato Baumann

LUIS BECCARIA

LUIS BÉRTOLA

Luiz Carlos Bresser-Pereira

Mario Cimoli

JOHN COATSWORTH

Robert DeVLIN

Carlós De Miguel

RicARDo FFrEnCh-DAVIS

Norman Girvan

Daniel Heymann

Martín Hopenhayn

Akio Hosono

Graciela Moguillansky

Juan Carlos Moreno-Brid

José Antonio Ocampo

Carlota Pérez

Gert Rosenthal

Paul Schreyer

Barbara Stallings

ANDRAS UthoFF

Roв Vos 